\title{
Construction of Cross-Cultural Identity by Language Choice and Linguistic Practice: A Case-Study of Mixed Hong Kong-Mainland Identity in University Contexts ${ }^{*}$
}

\author{
Tao Gong ${ }^{1}$, Lan Shuai ${ }^{2}$, Jia Liu ${ }^{1}$ \\ ${ }^{1}$ Department of Linguistics, University of Hong Kong, Hong Kong, China \\ ${ }^{2}$ Department of Electrical and Computer Engineering, Johns Hopkins University, Baltimore, USA \\ Email: gtojty@gmail.com, tina.liujia@gmail.com, susan.shuai@gmail.com \\ Received May $5^{\text {th }}, 2013$; revised June $7^{\text {th }}, 2013$; accepted June $14^{\text {th }}, 2013$
}

Copyright (C) 2013 Tao Gong et al. This is an open access article distributed under the Creative Commons Attribution License, which permits unrestricted use, distribution, and reproduction in any medium, provided the original work is properly cited.

\begin{abstract}
Studying relations between language and speaker's identity is an interdisciplinary field that involves intersections among language, culture, and society. By examining the language choice and linguistic practice, especially code-mixing and code-switching, of the Mainland China students who are studying in universities of Hong Kong, we reveal a mixed Hong Kong-Mainland identity in these students: those who hold a Mainland-oriented identity tend to have a Putonghua-dominated language choice and linguistic practice, whereas those who embrace a Hong Kong-oriented identity tend to prefer a Cantonese-dominated choice and practice. This mixed identity helps better conceive the social image of Mainland immigrants in Hong Kong and discuss the cross-cultural identity formed by linguistic practice.
\end{abstract}

Keywords: Cross-Cultural Identity; Linguistic Practice; Code-Mixing; Code-Switching

\section{Introduction}

Language is the primary resource and carrier for enacting identity and membership of social groups (Tong et al., 1999; Miller, 2000). Analyzing relations between language and speaker's identity is insightful to decipher the intrinsic characteristics of language, culture, and society. This line of research was pioneered by the Asian-American study addressing the mixed identity triggered by interactions between the official language in the American society (English) and those used by descendants of Asian-American immigrants (Bucholtz \& Hall, 2005). Until now, there have been many studies based on different populations and many relevant theories explaining the formation or change of various types of identities (e.g., Trueba, 1989; Norton, 1995; McNamara, 1997).

Simply put, identity is the social positioning of self and other (Bucholtz \& Hall, 2005). Instead of being a stable or pre-existing concept, identity is a discoursive construct not emerging at a single analytic level, but operates during interactions; in other words, socio-cultural interaction is the primary means by which identities are constructed and socialized (Ochs, 1993). In addition, identity is closely associated with language, and deeply rooted in cultural beliefs or values (ideologies) about the sorts of speakers who produce particular sorts of language (Bucholtz \& Hall, 2005). Some scholars even define identity as the linguistic construction of membership in one or more social groups or categories (Blot, 2003). Furthermore, the association between language and identity is bi-directional. On the one hand, lan-

"This work is supported by the Seed Fund for Basic Research in the University of Hong Kong. guage fulfills a function of expressing identity (Maass \& Arcuri, 1996). For example, from features (e.g., dialect, accent, pronunciation, lexical choice, and language choice) shown in a speaker's language production, one may tell the speaker's place of origin, gender, social status, educational background, etc. On the other hand, stereotypical use of language and linguistic resources also contribute to the construction of identity (Bucholtz, 2004). Finally, in a mixed culture formed by people from a variety of language groups, the issue of language and identity is also linked with language contact (the prolonged association between speakers of different languages, Thomason \& Kaufman, 1988). Two outcomes of contact, code-switching (alternation of languages within a conversation, Matras, 2009) and code-mixing (insertion of a word/ phrase into an utterance/sentence formed in a particular base or frame language, Muysken, 2000), are informative to issues concerning language and identity. All these suggest that socio-cultural interactions, language contact, and identity are closely correlated, and cannot be studied separately.

Hong Kong, as a mixed community formed by people from a variety of cultures, is a suitable place for studying issues about socio-cultural interactions, language contact, and identity. Previous studies in this line usually focused on Cantonese-English bilingualism and code-mixing or code-switching between English and Cantonese. For example, Chen (2005) discovered two socially distinctive types of code-mixing styles between English and Cantonese, and Ho (2007) studied the insertion of English lexical items into Cantonese sentences. Other studies investigated the socio-cultural status of Cantonese and English. For example, Cheung (1985) viewed English as the "language of power" and Cantonese as the "language of solidarity", and 
Gibbons (1987) found that English was closely associated with higher social status and educational background, and considered more prestigious compared to Cantonese. As for studies of identity, Mau (2005) summarized the historical development of the Hong Kong identity. This identity is quite distinct from the Mainland identity: although older generations of Hong Kong people generally recognized themselves as absolute Chinese, younger generations started to develop a unique identity, deliberately highlighting differences between Hong Kong people and Mainlanders. This was mainly due to two factors: the loosening of emotional ties to Mainland, as younger generations usually grew up in Hong Kong; and the economic prosperity of Hong Kong, making Mainland China an underdeveloped region. Although the sovereignty hand-over in 1997 reduced the gap between Hong Kong and Mainland China by reminding Hong Kong people of their Chinese identity (Mau, 2005), Hong Kong people still maintained the general perception viewing themselves as both Chinese and "Hongkongese" (Bolton \& Luke, 1999; Pennington, 1998).

Apart from Cantonese-English contact, in Hong Kong, sociocultural interactions between Mainlanders and Hong Kong local residents have become extremely frequent, especially after 1997 , and contact between Putonghua and Cantonese is playing important roles in many socio-cultural aspects. Many studies on language use in Hong Kong have recognized Putonghua as one of the available linguistic resources being increasingly important (e.g., Cheung, 1985), but little emphasis was put on Putonghua-Cantonese contact. Although previous work on identity traced the development of the Hong Kong identity from the past till now, little work actually addressed the identity of the Mainland groups in Hong Kong.

In this paper, we address our attention to the PutonghuaCantonese contact predominantly occurring in a particular Mainlander group and in a particular context. To be specific, we focus on the Mainland students who have been studying in universities of Hong Kong for three to four years, and explore their construction of identity via daily interactions with Hong Kong local students. Background of this Mainlander group in Hong Kong is given in Appendix A. Our discourse analysis on the interview data collected from a group of such Mainland students explicitly shows that these Mainland students can form their identity by consciously choosing languages between $\mathrm{Pu}-$ tonghua and Cantonese and inserting Cantonese lexical items into Putonghua sentences in various conversational situations in a university context. Two types of identity emerge in this process. The Mainland-oriented identity is marked by the higher frequency of using Putonghua than Cantonese, and reluctance to incorporate Cantonese lexical items into Putonghua sentences, whereas the Hong Kong-oriented identity is marked by the more obvious tendency in switching from Putonghua to Cantonese in different conversational situations, and adoption of a variety of colloquial Cantonese lexical items in Putonghua sentences. Although Mainland students only form one of the many cultural groups in Hong Kong, our research discovering this mixed identity formed by this group can shed some light on future studies of larger Mainland immigrant communities and relevant socio-cultural phenomena in Hong Kong.

\section{Materials and Methods}

Following the socio-cultural linguistic approach proposed by
Bucholtz \& Hall (2005), we construct a dialog-like interview and ask several language choice and linguistic practice questions during the interview, and then, conduct analyses on these discourse data. Among the five principles raised by Bucholtz \& Hall (2005), including emergence, positionality, indexicality, relationality and partialness, we concentrate on indexicality and relationality, which are the most explicit principles reflecting the socio-cultural and inter-subjective nature of identity. We examine the language choices of these Mainland students in social settings of a university context, and two types of linguistic practice, namely code-mixing and code-switching between Putonghua (the mother tongue of Mainland students) and Cantonese (the local linguistic resource). These choices and practices can be directly observed in these students' answers to particular questions and their language production during the interview. From the socio-cultural perspective, Blom \& Gumperz (1972) further divided code-mixing into two categories: situational switching, wherein a change in linguistic form represents a changed social setting; and metaphorical switching, referring to the use of two language varieties within a single social setting. In our study, we focus on metaphorical switching and examine the change of Putonghua and Cantonese within the same social setting. Meanwhile, code-mixing of linguistic items in the same utterance can occur at various (phonological, lexical, grammatical, and orthographical) levels (Ho, 2007). In our study, we focus on lexical items by analyzing the insertion of Cantonese colloquial items in Putonghua sentences.

13 Mainland students (4 males, 9 females, age range 22 - 24) who had been studying in universities in Hong Kong for three to four years participated in our study. They all signed the consent form before the interview and got paid after completing the interview. All participants had a native proficiency of Putonghua, despite their different hometowns and distinct regional dialects in Mainland China. Nearly all participants viewed Putonghua as their mother tongues, and three to four years of living in Hong Kong gave them sufficient time to socially interact with local students and pick up Cantonese, the local dialect. They were all competent and comfortable in using Cantonese whenever necessary or suitable in conversational settings.

Quantitative and qualitative data were collected from the participants during the $20-30$ minutes interviews. Putonghua was used throughout the interview, except for occasions for explaining or elaborating examples of Cantonese words or sentences. During the interview, participants answered a number of interview questions in the same order. Audio recording was also conducted for transcription and discourse analysis.

We designed three types of interview questions (basic information, starting questions, and situational questions, see Appendix B). Starting and situational questions were designed to respectively record five aspects of linguistic practice: situational questions 1 - 9 recorded code-switching and language choice in different conversational situations; starting questions 9 - 11 recorded code-mixing between Putonghua and Cantonese on lexical level; starting questions 7 and 8 recorded frequency of using Cantonese; starting questions 2, 3, and 6 recorded attitudes toward Cantonese; and starting questions 12 - 15 recorded nonlinguistic practice concerning social interaction habits and perceptions of Mainland and local students. The data collected were analyzed from these five aspects of linguistic practice. Quantitative data were visualized in histograms, qualitative data obtained by open-ended questions on participants' perceptions of Mainland students (e.g., Starting question 14) were analyzed 
using thematic analysis (Braun \& Clarke, 2006) and shown in tables, and qualitative data about participants' personal experiences were excerpted from transcriptions.

\section{Results}

\section{Language Choice and Code-Switching}

The situational questions recorded the choice and codeswitching between Putonghua and Cantonese in various conversational situations. The answers to them showed that the participants preferred Cantonese over Putonghua in daily conversations. Cantonese was selected pre-dominantly in seven out of nine situations, whereas Putonghua was chosen only in two situations where interlocutors (local students) speak Putonghua first. In addition, among the nine situations, situations 3, 6, 7, 8, and 9 involved active language choice: the participants initiate conversations in these situations, and any language previously spoken may not affect their choice. Answers in these situations could reflect the participants' conscious language choice. In contrast, situations 1,2, 4, and 5 involved passive language choice: the participants' use of language may be affected by interlocutor's use of language.

As shown in the data, Cantonese was used to initiate conversations (see Figure 1(a)). In situations 1 and 2, language choice was dependent on the language used by local students who started conversations. In situations 4 and 5, the participants tended to switch to the language used by interlocutors, regardless of the language used to initiate conversations (see Figure 1(b)).

\section{Code-Mixing at Lexical Level}

The participants not only recognized immediately the colloquial Cantonese words cited in starting question 9, but also provided many examples of Cantonese words and expressions to answer starting question 10 (see Table 1), which indicated that the participants knew lexical resources of Cantonese well, and could clearly distinguish them from those of Putonghua.

Answers to starting question 11 also revealed that the participants tended to insert Cantonese words into Putonghua sentences, and generally regarded such practice as natural or normal in their daily conversations and a habitual practice frequently seen in their Mainland peers in university. Figure 2 lists the reasons for such code-mixing, among which the vividness of Cantonese expressions and lack of proper Putonghua translation were chosen by nearly $64 \%$ of the participants, but other reasons also contributed to such code-mixing.

\section{Frequency of Using Cantonese}

Answers to starting question 7 revealed that Putonghua was used more often than Cantonese, and only one participant stated that the frequencies of using Putonghua and Cantonese were about the same. Nonetheless, the use of Cantonese was inevitable in daily conversations: $46.2 \%$ of the participants used Cantonese $1-5$ hours a week, and $30.8 \% 6$ - 10 hours a week, altogether $77 \%$ of the whole group. The variation in the frequency of using Cantonese was mainly due to the following 3 reasons:

1) Accommodation environment: the participants living in residential halls with local roommates and having opportunities

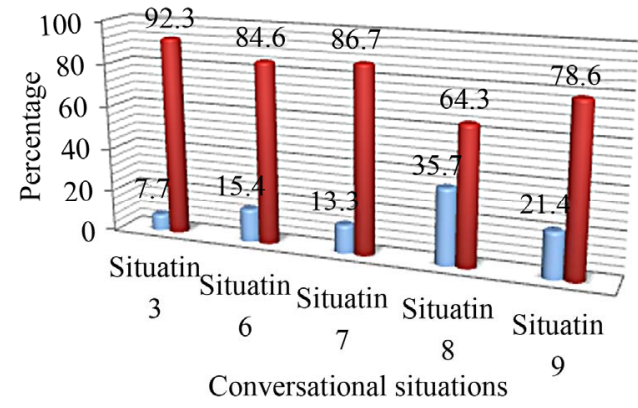

(a)

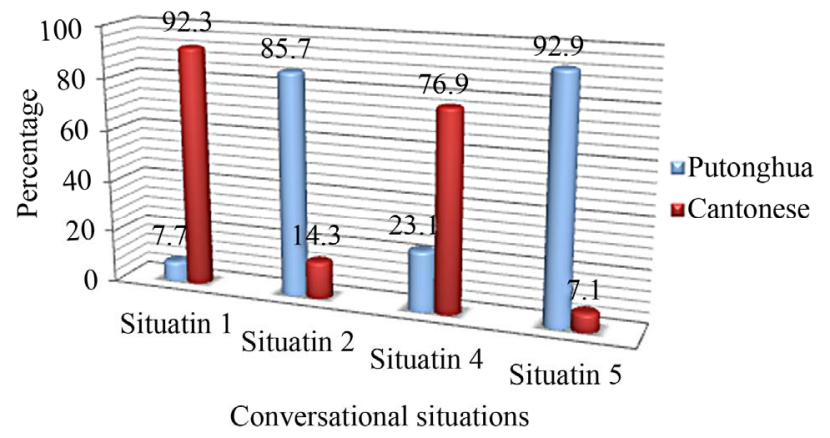

(b)

Figure 1.

Language choice in situations 3, 6, 7, 8, and 9(a) and in situations 1, 2, 4, and 5(b). Each value is a proportion of participants choosing Putonghua or Cantonese in a particular situation.

Table 1.

Cantonese expressions in answers to starting question 10, together with the corresponding Putonghua expressions and English translations.

\begin{tabular}{ccc}
\hline Cantonese & Putonghua & English \\
\hline 收皮 & 走开 & Go away \\
嗰陣時 & 那时 & At that time \\
餸 & 菜 & Dish \\
嘢飲 & 饮料 & Beverage \\
憼居 & 憼俊 & Slow, stupid \\
攰 & 累 & Tired \\
有米 & 富有 & Rich \\
講大話 & 说谎 & Lie \\
勁 & 厉害 & Be good at, super \\
孤寒 & 吝啬 & Mean \\
折朵 & 宅 & Prefer staying indoor \\
着數 & 优惠 & Discount \\
通頂 & 通宵 & Stay over night \\
水鱼 & 易被骗的人 & People who are easy to coax \\
大頭蛝 & 马虎的人 & Careless people \\
\hline
\end{tabular}

to take part in hall-based activities tended to have a higher frequency of using Cantonese than those living off campus with Mainland peers;

2) Percentage of local classmates: the participants whose academic programs involved a large percentage of local students but a relatively low percentage of Mainland students tended to have more chances to use Cantonese in academic contexts; 


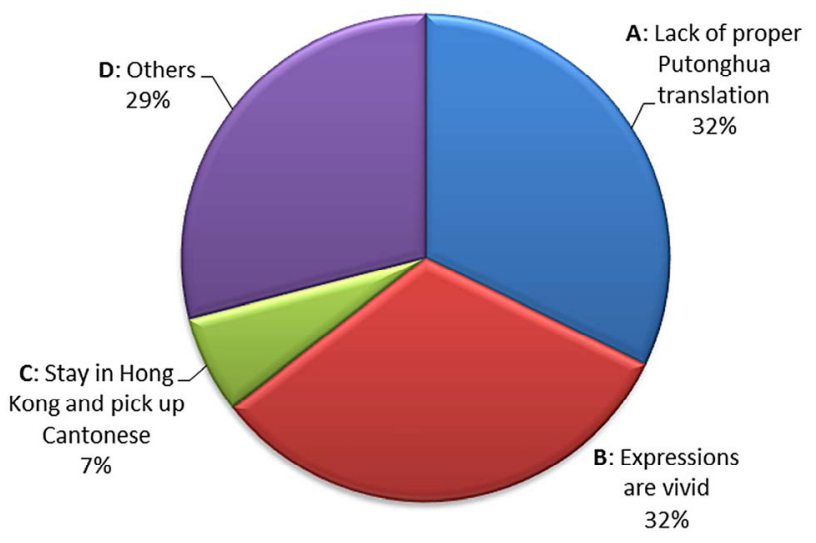

Figure 2.

Answers to Starting question 11.2. Each value is the proportion of the participants who select a particular reason for code-mixing.

3) Attending Cantonese course: during the Cantonese course, the frequency of using Cantonese was relatively higher than that in the semesters without such course.

\section{Attitudes toward Cantonese}

Except two participants who spoke Cantonese in their domestic environments, and hence had practiced Cantonese for more than five years, $53.8 \%$ of the participants regarded that Cantonese learning occurred in their daily lives after living in Hong Kong, and only $30.8 \%$ stated that the Cantonese course in the first year or semester of their university lives was the actual learning time and opportunity. In addition, $61.5 \%$ of the participants deemed Cantonese not difficult to learn compared to other languages such as English or French, some deliberately mentioned that Cantonese was Chinese after all, but the others considered learning Cantonese quite hard. $69.2 \%$ of the participants who deemed Cantonese hard to learn stated that the hardest part came from the phonological (e.g., the subtle variation of tones) and lexical aspects (e.g., the difference in the use of certain lexical items) (see Figure 3). In contrast, 30.8\% of the participants did not mind making mistakes on those aspects, for them, being understood and able to communicate were enough.

\section{Non-Linguistic Practice}

Answers to starting questions 12 revealed that $84.5 \%$ of the participants tended to stick to their Mainland social circles, instead of breaking into the local circles. Main reasons for this include: 1) common language and topic for communication; 2) similar cultural background and shared memories; and 3) similar lifestyles.

As for academic activities such as in- or off-class group tasks, $72.2 \%$ of the participants who chose Mainland students to work with thought that Mainland students were generally more reliable, hard-working, efficient, and shared similar learning styles. However, this was based mainly upon the assumption that the participants already knew some Mainland students in the class. Given the situation where they did not know either Mainland or local students in the class, either type of students would be fine.

Personal experience regarding discrimination and unfairness generally covered the following areas: 1) Hong Kong students' use of impolite or insulting forms of address; 2) comments on

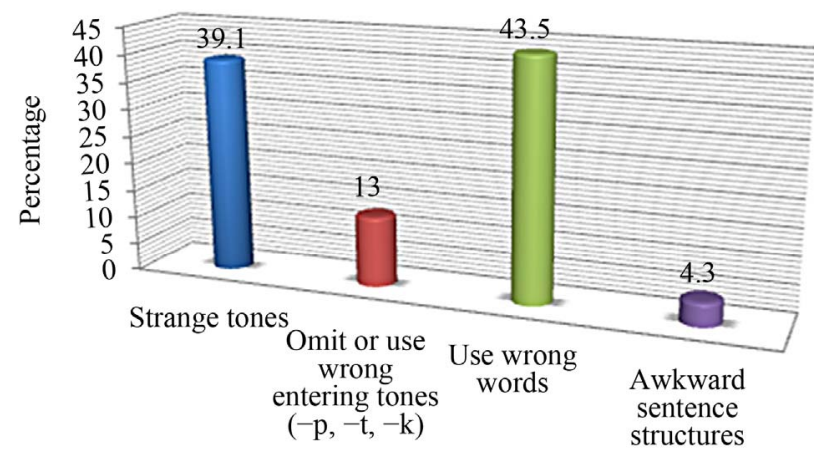

Difficult areas in Cantonese

Figure 3.

Answers to starting question 6. Each value is the proportion of the participants who select a particular aspect in Cantonese.

politically or socially sensitive issues (e.g. May 4th Movement); 3) Hong Kong students' sense of priority and prestige; and 4) sense of isolation and otherness.

Thematic analysis of the data indicated that these participants perceived themselves as being different from their local peers in social or academic aspects (see Table 2). In addition, although the interview questions focused on difference between Mainland and local students, some participants also mentioned the difference between Mainland students studying in Hong Kong and those studying in Mainland universities (see Table 3), indicating that they also perceived themselves as being distinctive from their Mainland peers having no living experience in Hong Kong. Furthermore, when asked to describe the image of Mainland students in Hong Kong, four out of 13 participants explicitly classified them into two stereotypical groups, one being more Mainland-like, and the other being more localized. Detailed analysis of this is shown in the next section.

\section{Discussion}

\section{Construction of a Hong Kong-Mainland Identity}

These participants constructed their Hong Kong-Mainland identities by both linguistic and non-linguistic practice.

As for linguistic practice, following the socio-cultural linguistic framework (Bucholtz \& Hall, 2005), identity emerges in interactions via the use of linguistic structures and systems ideologically associated with specific persons and groups. In the case of Mainland students in Hong Kong, Putonghua and Cantonese are available in daily interactions, with the former ideologically associated with the Mainland group and the latter strongly connected to the Hong Kong group. As shown in the data, inserting Cantonese lexical items into Putonghua sentences was a habitual linguistic practice by all participants. Knowing many colloquial Cantonese words also showed that the local linguistic resource, Cantonese, was available for the participants. Moreover, seen from Table 1, each Cantonese word provided by the participants has its equivalent but distinct Putonghua expression, but when wanting to convey those meanings, the participants would prefer Cantonese expressions, even if the sentence was in Putonghua. Such Putonghua-Cantonese code-mixing in Mainland students elucidates their dual associations with both the Mainland group, by using Putonghua sentences, and the Hong Kong group, by inserting colloquial Cantonese lexical items into those sentences. In addition, on the 
Table 2.

Stereotypical perceptions of Mainland students compared to local students.

\begin{tabular}{cl}
\hline Main themes & \multicolumn{1}{c}{ Subthemes } \\
\hline & Outfits: \\
& - Not fashion, lack of trendy items or accessories \\
& - More casual and comfortable (e.g. sportswear) \\
Appearance & Hair-style: \\
& - Less fancy, lack of fashionable style \\
& Make-up: \\
& - Seldom wear make-up \\
& Go to bed and get up early \\
& Be punctual \\
& Prefer going to the library \\
& Few extra-curricular activities \\
& Eating habits: \\
& - Prefer Chinese cuisines to Western ones \\
& - Less habitual afternoon-teas \\
& High GPA \\
Lifestyle & Hard-working \\
Academic & Prefer traditional learning methods (e.g. writing notes on \\
performance & papers instead of using laptops) \\
Cultural value & Better understanding of Mainland China \\
& Influenced by Hong Kong culture \\
\hline
\end{tabular}

Table 3.

Stereotypical perceptions of Mainland students in Hong Kong and their Mainland peers.

\begin{tabular}{cl}
\hline Main themes & \multicolumn{1}{c}{ Subthemes } \\
\hline Language & Use English words in Putonghua sentences \\
& Use Cantonese words in Putonghua sentences \\
& $\begin{array}{l}\text { More independent and individualized } \\
\text { Clear ambition and future goals } \\
\text { Personality \& value }\end{array}$ \\
\hline
\end{tabular}

aspects of code-switching and language choice, Cantonese was the dominant language used by the participants in various conversational situations with local students, especially when the participants initiated conversations. In summary, the results of code-mixing and code-switching collectively reveal Mainland students' frequent use of the local dialect, Cantonese, and their mother tongue, Putonghua. Through such linguistic practice, Mainland students have established a unique Hong KongMainland identity, ideologically distinctive from the identity of either Mainlanders or Hong Kong people.

As regards non-linguistic practice, evidence of the construction of the Hong Kong-Mainland identity also exists. From the socio-cultural perspective, identities are formed relationally through several overlapping aspects of the relationship between self and other (Bucholtz \& Hall, 2005). Among various aspects, producing similarity or difference between the self and other social groups is a typical way of articulating individuals' identities. By doing so, individuals consciously position themselves toward or away from a social group. These two processes were defined by Bucholtz (2004) respectively as: adequation, "the ideological creation of an interactionally sufficient but necessarily incomplete similarity between social groups or individuals" (p. 132); and 2) distinction, the ideological production of social difference" (p. 132, see also Irvine, 2001).

Seen from the non-linguistic practice of the participants, a strong tendency of sticking to the Mainland social circle was obvious, indicated by their choosing Mainland peers to hang out or work with. The main reason for this lies in the similarities of cultural backgrounds and lifestyles. By showing simi- larities among themselves and differences from local students, Mainland students position themselves toward the Mainland group through adequation, and meanwhile, away from the local group through distinction. In addition, the thematic analysis of the participants' perceptions of Mainland students in Hong Kong showed another tendency of their social positioning. Although Table 2 shows that participants generally perceived Mainland students as being distinct from local students in many aspects, which reflects the process of distancing from the local group, Table 3 shows that the participants also perceived themselves as being different from their Mainland peers not living or studying in Hong Kong, which hints their distinction from the Mainland group as well. In summary, Mainland students in Hong Kong positioned themselves between Mainlanders and local Hong Kong people, and constructed their identity by negotiating between these two groups.

\section{Two Types of Hong Kong-Mainland Identity}

The participants' descriptions of the image of Mainland students in Hong Kong revealed two types of Hong Kong-Mainland identity. The answers of two participants to starting questions 13 and 14 and situational questions elucidated these two types of identity. Note that although these participants explicitly revealed their distinctive identities, there was no clear-cut between these two types. It is meaningless to classify each participant into either type; instead, it is the degree of orientation toward either type that matters.

The participants holding the Mainland-oriented identity generally position themselves more toward the Mainlander group, by sticking to Putonghua over Cantonese in conversational situations and adequating toward Mainlander group via non-linguistic practice. For example, Dan (24 years old, male) had been studying in Hong Kong for 4 years at the time of the interview. He chose Putonghua as answers to all situational questions, yet, his Cantonese proficiency was quite high. No matter initiating a conversation or responding to his interlocutors, $\mathrm{Pu}$ tonghua was definitely his first choice. Since individuals' language choice indicates their intended association with certain social groups (Johnstong \& Bean, 1997), Dan's conscious choice of Putonghua over Cantonese reveals his strong sense of affiliation to his Mainland identity, which is also shown in the interview, "the reason why I speak Putonghua is that my identity is a Mainland student" (see Appendix C). He thought that speaking Putonghua was an indication of his origin from place where Putonghua was spoken. His excessive use of Putonghua in daily communications was strongly related to his expression and maintenance of his Mainland identity. Compared to other participants, Dan intended to form a Mainland-oriented type of identity through his Putonghua-dominated linguistic practice in various conversational situations. In addition, non-linguistic practices, such as a lower frequency of using Cantonese $(<1$ hour/week), holding negative attitudes toward Mainland students who speak much Cantonese, and regarding them as a "loss of identity" (see Appendix C), also supported his Mainland-oriented identity type.

In contrast, the participants who embrace the Hong Kongoriented identity generally have better blended with the local society. As for linguistic practice, they are apt to choose Cantonese over Putonghua in most interactional situations provided. As for non-linguistic practice, they also show higher frequencies of social interactions with local students. For example, 
Wan (23 years old, female) had been studying in Hong Kong for 3 years at the time of the interview. She chose Cantonese in 8 out of 9 situations in the interview. The only situation she chose Putonghua was "when you have started a conversation in Cantonese with a local student but receive a reply in Putonghua" (situation 5). She thought that this situation occurred when local interlocutors wanted to practice Putonghua, so she spoke Putonghua to fulfill their expectation. Compared to Dan's use of Putonghua, which functioned as an indicator of his Mainland identity, Wan's use of Putonghua was to benefit local students by adjusting her language according to their preference. According to Johnstone \& Bean (1997), Wan's language choice indicated her identification with local students, adjusting her own language not because of her own identity, but because of her intimate relationship with her local friends. In addition, Wan's non-linguistic practice also supported her Hong Kongoriented identity. For example, the number of local friends she had was about the same as that of her Mainland friends, since she joined a student organization full of local students, and was willing to work with local students when doing group tasks.

\section{Conclusion}

The community of Mainland students studying in Hong Kong has been growing rapidly in recent years, which bring many challenges and difficulties to these students living in such a multi-cultural society in Hong Kong. Struggling between Putonghua and Cantonese and identity-related issues are two typical obstacles that Mainland students encounter. In this paper, we examine the construction of Mainland students' identity through their language choice and linguistic interactions with local students, and discover two types of Hong Kong-Mainland identity constructed through linguistic practice of code-mixing and code-switching between Cantonese and Putonghua and non-linguistic practice of adequation and distinction. The linguistic experience of such immigrant students forms a complex negotiation of their social identity in the new society, which is a process having profound implications for their attitudes toward their own language and the local language (McNamara, 1997; Miller, 2000).

Due to certain constraints, the number of participants in this study is limited and most participants were from the University of Hong Kong, thus making the findings in this paper representative only for a specific group of students rather than the whole Mainland students in Hong Kong. Future large-scale research and systematic analysis of Mainland students' linguistic practices and identities from the socio-cultural linguistic perspective will help better understand this particular social community in Hong Kong.

\section{REFERENCES}

Blot, R. K. (2003). Language and social identity. London: Praeger. Bolton, K., \& Luke, K. K. (1999). Language and society in Hong Kong: The social survey of languages in the 1980's. Hong Kong: University of Hong Kong, Social Sciences Research Centre.

Braun, V., \& Clarke, V. (2006). Using thematic analysis in psychology. Qualitative Research in Psychology, 3, 77-101. doi:10.1191/1478088706qp063oa

Bucholtz, M. (2004). Styles and stereotypes: The linguistic negotiation of identity among Laotian American youth. Pragmatics, 14, 127-147.

Bucholtz, M., \& Hall, K. (2005). Identity and interaction: A sociocultural linguistic approach. Discourse Studies, 7, 585-614. doi: $10.1177 / 1461445605054407$

Chen, H. Y. (2005). The social distinctiveness of two code-mixing styles in Hong Kong. In J. Cohen, K. T. McAlister, K. Rolstad, \& J. MacSwan (Eds.), Proceedings of the 4th international symposium on bilingualism (pp. 527-541). Somerville, MA: Cascadilla Press.

Cheung, Y.-S. (1985). Power, solidarity, and luxury in Hong Kong: A sociolinguistic study. Anthropological Linguistics, 27, 190-203.

Gibbons, J. (1987). Code-mixing and code-choice: A Hong Kong case study. Clevedon: Multilingual Matters.

Ho, J. W. Y. (2007). Code-mixing: Linguistic form and socio-cultural meaning. The International Journal of Language, Culture and Society, 21, 23-30.

Hong, C. (2007). Hong Kong stories: Mainland students come to Hong Kong. Hong Kong: University of Hong Kong, Journalism \& Media Studies Centre (http://jmsc.hku.hk/hkstories/content/view/214/73/).

Irvine, J. T. (2001). "Style" as distinctiveness: The culture and ideology of linguistic differentiation. In P. Eckert, \& J. Rickford (Eds.), Style and sociolinguistic variation (pp. 21-43). Cambridge: Cambridge University Press.

Johnstong, B., \& Bean, J. M. (1997). Self-expression and linguistic variation. Language in Society, 26, 221-246. doi:10.1017/S0047404500020911

Li, M., \& Bray, M. (2007). Cross-border flows of students for higher education: Push-pull factors and motivations of Mainland Chinese students in Hong Kong and Macau. Higher Education, 53, 791-818. doi:10.1007/s10734-005-5423-3

Maass, A., \& Arcuri, L. (1996). Language and stereotyping. In C. N. Macrae, C. Stangor, \& M. Hewstone (Eds.), Stereotypes and stereotyping (pp. 193-226). New York: Guilford Press.

Mau, W.-Y. A. (2005). Cantonese: Language or dialect? MA Dissertation. Hong Kong: University of Hong Kong.

McNamara, T. (1997). Theorizing social identity. TESOL Quarterly, 31, 561-567. doi:10.2307/3587838

Miller, J. M. (2000). Language use, identity, and social interaction: Migrant students in Australia. Research on Language \& Social Interaction, 33, 69-100. doi:10.1207/S15327973RLSI3301_3

Muysken, P. (2000). Bilingual speech: A typology of code-mixing. Cambridge: Cambridge University Press.

Norton, B. (1995). Social identity, investment, and language learning. TESOL Quarterly, 29, 9-32. doi:10.2307/3587803

Ochs, E. (1993). Constructing social identity: A language socialization perspective. Research on Language and Social Interaction, 26, 287306. doi:10.1207/s15327973rlsi2603 _ 3

Pennington, M. C. (1998). Language in Hong Kong at century's end. Hong Kong: Hong Kong University Press.

Thomason, S. G., \& Kaufman, T. (1988). Language contact, creolization, and genetic linguistics. Berkeley, CA: University of California Press.

Tong, Y.-Y., Hong, Y.-Y., Lee, S.-L., \& Chiu, C.-Y. (1999). Language use as a carrier of social identity. International Journal of Intercultural Relations, 23, 281-296. doi:10.1016/S0147-1767(98)00039-X

Trueba, H. (1989). Raising silent voices: Educating the linguistic minorities for the 21st century. New York: Newbury House. 


\section{Appendix A: Background of Mainland Students in Hong Kong}

Universities in Hong Kong started to recruit Mainland students in 1998, and the number of admitted students has been increasing year by year ever since then. According to the statistics, in 2010, over 1400 Mainland students were admitted by in total 12 universities in Hong Kong (Xinhua News, 2010/07/21, http://news.xinhuanet.com/english2010/china/2010-07/21/c_13 408010.htm). The high-quality education, international environment, and large amount of scholarship make universities in Hong Kong very attractive to students in Mainland China. Attending universities in Hong Kong has been viewed by many Mainland students as both the destination of high education and stepping-stone for international development (Li \& Bray, 2007). In addition, Mainland students in Hong Kong also have received positive comments from university professors. They are generally described as hard-working, intelligent in terms of academic performance, and getting along quite well with local and international students.

Nonetheless, along with the growing number of Mainland students in Hong Kong are various problems and challenges. For example, among the 10 major difficulties faced by Mainland students in Hong Kong, "different social dialect" and "being Mainlanders in Hong Kong" are the most frequent, and struggling between their mother tongue, Putonghua, and the local dialect, Cantonese, is the most critical challenge to Mainland students (Hong, 2007). Moreover, Mainland students in Hong Kong generally experience a gap between themselves as Mainlanders and Hong Kong people, due to various factors, among which language barrier is the dominant one. The sense of being an outsider, instead of totally blending into the local community as an insider, leads to Mainland students' lack of emotional security and loss of identity.

\section{Appendix B: Translated Interview Questions}

Basic Information: please fill in the blanks in the following questions.

Name: Gender: Age:

Years studying at $\mathrm{HK}$ : (University:

Hometown in China:

Starting Questions: please indicate your choice or answers to the following questions.

1) Are you a native speaker of Putonghua? Yes/No

2) How long have you studied Cantonese?

2.1) Do you find Cantonese hard to learn?

2.2) Do you find it necessary to learn Cantonese in your life in HK?

3) Did you start learning Cantonese before coming to HK? Why?

4) How did you learn Cantonese?
A. Required Cantonese course offered by university
B. Communicating with local friends
C. Tutoring lessons
D. Watching TV series in Cantonese
E. Other, please specify

5) How do you describe your Cantonese proficiency?

A. Fluent (in both daily communication and academic performances)

B. Enough for daily communication only

C. Not quite good

\section{Extremely poor}

6) Do you think you have accent in speaking Cantonese? Which area(s) below do you think you have problem with? (Or have you ever heard local students commented on your accent in the following areas?)

A. Tones are strange (some of the tones are difficult to grab)

B. Omit or use wrong check tones (e.g. the pronunciation of “十 sup”, “一 yat”, “食 sik")

C. Use wrong words (e.g. directly translate Putonghua into Cantonese when a Cantonese word should be used. 教室 instead of 课室/班房)

D. Awkward sentence structures (e.g. Putonghua structure instead of Cantonese one. 我卑你钱 instead of 我卑钱 你)

6.1) Do you pay special attention to these areas when communicating with local students in Cantonese? Or you think it's OK if you could be understood perfectly?

7) How often do you use Cantonese in your daily life?

A. $<1$ hour/week

B. 1 - 5 hours/week

C. 6 - 10 hours/week

D. $>10$ hours/week

8) In general, which language do you use more often, Putonghua or Cantonese?

9) Do you know the meaning of these Cantonese words? 搏尽 (studying or working hard), 吹水 (chatting casually), 挞皮 (not trying hard)...

10) Do you know other Cantonese colloquial expressions like the examples shown above? E.g.

11) Do you sometimes use these above Cantonese expressions in your conversation with Mainland friends?

11.1) If you do not do so, have you ever heard some of your friends or others do so?

11.2) If you do so, why?

A. Can't find proper or exact Putonghua translation of those expressions

B. Those expressions are very vivid

C. I want to show that I have been in Hong Kong for some time and have picked up some Cantonese

D. Other, please specify

11.3) If you do so, are these expressions pronounced in $\mathrm{Pu}-$ tonghua or in their original Cantonese pronunciation?

12) Whom do you usually hang out with, friends from Mainland or local friends from Hong Kong?

If Mainland friends, why? Why not more local friends?

If local friends, why? Practice Cantonese? Want to be part of their clique? Differentiate yourself from other Mainland students?

13) Have you ever been discriminated or unfairly treated or teased by local students regarding your Mainland identity?

14) Can you describe the image of Mainland students who study in Hong Kong University? Are there any typical features of them that make them different from local students on campus?

15) When doing group assignments (project, presentation, essay...), whom do you want to work with more willingly, local students or Mainland students? Why?

Situational Questions: please select from Putonghua (P) and Cantonese (C) in the following situations.

1) A local student starts a conversation with you using Cantonese. $\mathrm{P} / \mathrm{C}$

2) A local student starts a conversation with you using Putonghua. 
$\mathrm{P} / \mathrm{C}$

3) You want to initiate a conversation with a local student. P/C

4) You have started a conversation in Putonghua with a local student but receive a reply in Cantonese. $\mathrm{P} / \mathrm{C}$

5) You have started a conversation in Cantonese with a local student but receive a reply in Putonghua. $\mathrm{P} / \mathrm{C}$

6) During in-class discussions or activities, your other groupmates are talking in Cantonese. $\mathrm{P} / \mathrm{C}$

7) When you go to your program office or other administrative sections (e.g. academic office, CEDARS, etc.) at university to ask for some help or information. $\mathrm{P} / \mathrm{C}$

8) When you order food or in the canteens on campus. P/C

9) When you talk to librarians in the library. P/C

\section{Appendix C: Selected Translated Transcriptions between Interviewer (I) and Interviewee Dan (D)}

D: I feel that some Mainland students speak too much Cantonese. They regard Cantonese as their mother tongue... they lost themselves, that is, the loss of their identity. And I think the reason why I speak Putonghua is that my identity is a Mainland student.

I: Well, that is, you think that speaking Putonghua is the indication of your identity, right?

D: Yeah, yeah, I think so. Because, I originally come from a place where Putonghua is spoken... Then why you ask me to speak Cantonese instead of me asking you to speak Putonghua? 